\title{
A Balanced Scorecard for Open Innovation: Measuring the Impact of Industry-University Collaboration
}

\author{
Myrna Flores ${ }^{1}$, Ahmed Al-Ashaab ${ }^{2}$, and Andrea Magyar ${ }^{2}$ \\ ${ }^{1}$ Research and Networking, Processes and IT, \\ CEMEX Global Center for Technology and Innovation, \\ CEMEX Research Group AG, Römerstrasse 13 CH-2555 Brügg, Switzerland \\ ${ }^{2}$ Decision Engineering Centre, SAS, Cranfield University, United Kingdom \\ myrnafatima.flores@cemex.com, a.al-ashaab@cranfield.ac.uk, \\ magyar.andy@gmail.com
}

\begin{abstract}
The Balanced Scorecard (BSC) can be considered as a strategic measurement tool. Since its first publication by Norton and Kaplan in the early 1990's, many companies have applied it to measure four key aspects of their organisations' performance: Financial, Customer, Internal Business Process, Learning and Growth. Although it is widely used in the business arena, this original BSC was not developed to assess the impact of collaborative research projects under an open innovation strategy, where the outputs of research and development $(\mathrm{R} \& \mathrm{D})$ developed by collaborative projects undertaken by industry and universities should be measured in a different way. In fact, many companies are losing important opportunities to spur their R\&D results by not being able to quantify the results of such collaborations. Therefore, this paper will propose a Scorecard to measure the outcomes of collaborative research. It is important to recall that this scorecard has been developed during a collaborative research project by CEMEX Research Group AG (Switzerland) and Cranfield University (UK). During such project, a survey was developed to carry out eleven face-to-face interviews in a sample of ten companies in UK, which provided important inputs to design such strategic scorecard. It was confirmed that a collaborative balanced scorecard is a very useful tool to measure, track and improve the impact of conducting collaborative projects with universities.
\end{abstract}

Keywords: Balanced Scorecard, Open Innovation, Industry-University Collaboration.

\section{Introduction}

The Balanced Scorecard (BSC) is a simple and useful measurement tool to track companies' performance [1]. It incorporates four main perspectives. Only one is related to the financial measures, which usually is the main concern of firms when measuring profitability and performance. Therefore, when the BSC was initially proposed, it integrated other three key elements to measure business success: customer satisfaction, internal business process and the ability to learn and grow. As a result, the traditional view to only measure the financial indicators of a firm was complemented in the BSC 
to obtain the following four perspectives: 1) Financial, 2) Customer, 3) Internal Business Process, 4) Learning and Growth. The perspectives are the views of a company on particular vantage points which cover the main company's activities [2]. Those perspectives need to be assessed. This is possible due to the definition of the four elements proposed by Kaplan and Norton (1996) as shown in Figure 1: Objectives, Measures, Targets and Initiatives.

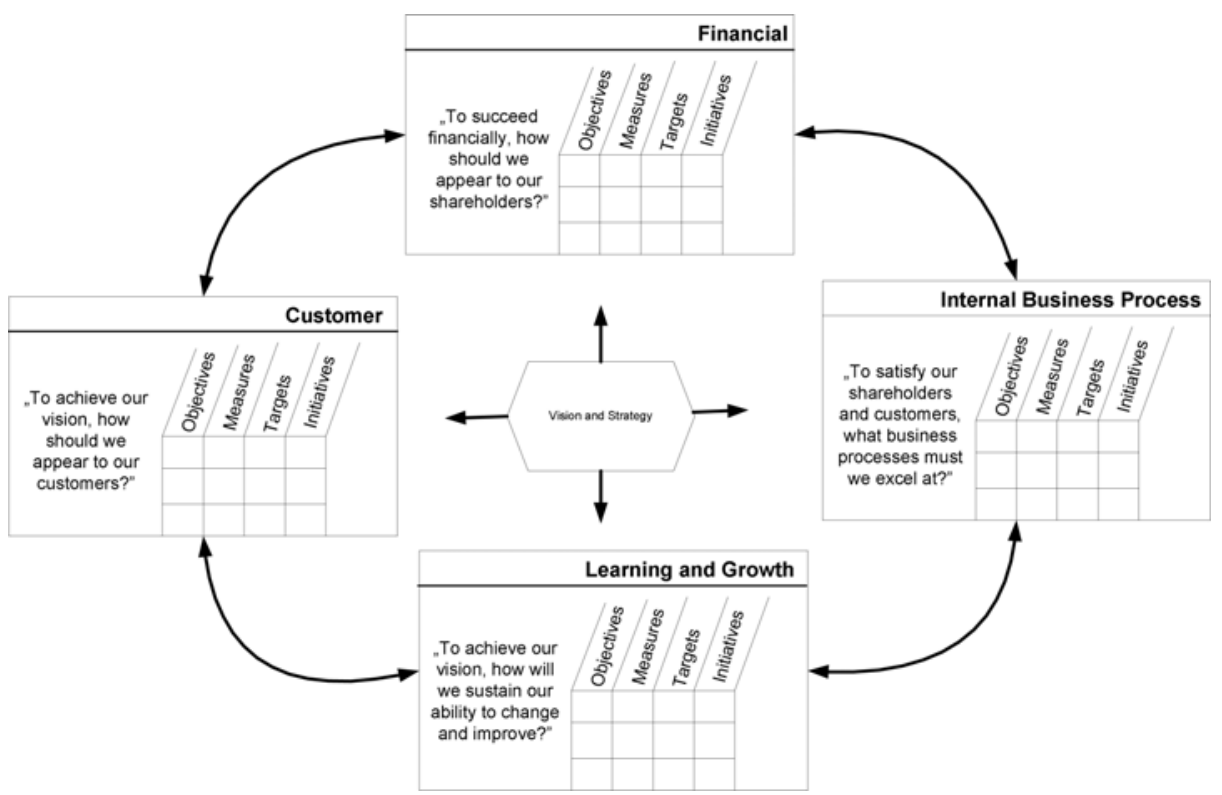

Fig. 1. The Balanced Scorecard as a Framework to translate strategy into action (Kaplan and Norton, 1996 [1])

The first element "objectives" focuses on clarifying and translating the company's vision into strategy. Companies need to define the aims and the achievements they want to reach in the future. This would allow creating a strategy that would enable them to reach their goals. The second element "measures" looks forward to communicating and linking the objectives with the results. Firms have to identify quantitative indicators for each objective. Therefore, the defined objectives and measures need to be distributed by means of newsletters, board meetings, companies' radios and electronic networks to make every worker aware of them. The third "target" element means planning and setting qualitative or quantitative goals. In other works, firms need to set numbered targets for each measured perspective. These targets may reflect the future aims in short or long term periods. The fourth and last element "initiatives" means using the strategic feedback and learning from past errors to improve. It relates to doing activities to facilitate reaching the targets [3].

When companies set out their future targets and plan them, they need to examine what they did during the last period in order to continuously improve. This supplies them with strategic feedback. Companies can then move forward with their business and decide for new initiatives or projects. Therefore, the Balanced Scorecard is used 
as a framework that emphasizes the importance of each of the four perspectives. It helps translating strategy into action [4]. Unfortunately, the traditional BSC is neither appropriate nor useful to measure the innovation outcomes when implementing an open innovation model when companies need to collaborate with external partners to develop new solutions [5], [6]. Therefore, this paper will present the outcomes of a collaborative research project where a novel Balanced Scorecard was designed to measure the outcomes of collaborative efforts with academia carried out in a particular area in CEMEX: Research and Networking in Processes and IT.

\section{A Scorecard for Open Innovation: The Need to Measure Industry-University Collaborative Environments}

It is important to highlight that the original BSC proposed by Norton and Kaplan was developed before the current growing trends to innovate and collaborate to be competitive in the global business environment. Therefore, the four proposed perspectives considered the firm as a closed entity and did not identified as strategic the current need from companies to be leaders at product and process innovations to remain competitive. Additionally, such first scorecard did not consider the fact that many new developments would be carried out along with external partners, such as universities or research institutions outside the firm boundaries.

R\&D to achieve innovations is a very costly, risky and lengthy process. Nowadays, it is difficult and challenging for companies to innovate in short periods of time in an ever increasing global market where customers' needs change quickly and the products' life cycles get shorter. Some of these concepts have been lately spread by several authors. For instance, Chesbrough [7] defines the traditional innovation process as a Closed Innovation Model. The reason is that all innovation activities are located inside the company from the ideas creation, development process, sales and marketing. In this case, companies think that they are the best on their field; they have enough knowledge and resources inside their firm boundaries to develop such new solutions. According to Viskari [8], there are four erosion factors that cause problems in such closed innovation model: 1) availability and mobility of skilled people, 2) venture capital market, 3 ) external options for ideas sitting on the shelf and 4) capability of external suppliers.

Therefore, the closed innovation model cannot satisfy the fast changing demands of global customers in a changing society. Chesbrough [7] defines the Open Innovation model as the use of purposive inflows and outflows of knowledge to accelerate internal innovation, and expand the markets for external use of innovation. In other words, the new value chain is the assembly of all the processes and related activities that are important from the beginning to the final customers' product or service, as each of those activities add value during the process. Opening up can allow companies to tackle some issues such as: high costs involved in $\mathrm{R} \& \mathrm{D}$, lack of skilled people and lack of knowledge inside the company.

In fact, many collaboration models have emerged to achieve more innovation outputs under collaborative environments, such as virtual organizations or living labs. As this is not a trivial matter, it should be considered a science where more research 
should be carried out to provide more tools and methodologies enabling more successful partnerships [9]. As a consequence, new models to measure collaboration outputs targeting value measurement systems have been also proposed [10].

In a nutshell, the Open Innovation concept strongly focuses on cooperation with others to achieve innovations, such as universities and research institutes. The main aim of corporate innovation with universities is to generate novel solutions improving business performance and also integrating new latent needs, such as sustainability. As a result, Chesbrough [11] defined six types of business models related to two aspects: Intellectual Property (IP) management and innovation process, as shown in Table 1. The adaptive business model, type 6, emphasizes the importance of the connection between the business model and the innovation process.

Table 1. Matrix of the Business Model Framework with the IP and innovation process (Source: Chesbrough, 2006 [11])

\begin{tabular}{|c|c|c|c|}
\hline & Business model & $\begin{array}{c}\text { Innovation } \\
\text { process }\end{array}$ & IP management \\
\hline Type 1 & Undifferentiated & None & NA \\
\hline Type 2 & Differentiated & Ad hoc & Reactive \\
\hline Type 3 & Segmented & Planned & Defensive \\
\hline Type 4 & Externally aware & Externally supportive & Enabling asset \\
\hline Type 5 & $\begin{array}{c}\text { Integrated innovative process } \\
\text { into the business model }\end{array}$ & $\begin{array}{c}\text { Connected to business } \\
\text { model }\end{array}$ & Financial asset \\
\hline Type 6 & $\begin{array}{c}\text { Adaptive (model is able to change } \\
\text { by the market needs) }\end{array}$ & $\begin{array}{c}\text { Identifies new business } \\
\text { models }\end{array}$ & Strategic asset \\
\hline
\end{tabular}

Companies can apply an adaptive business model and collaborate with universities on different research projects in order to be more competitive in the market [12]. Collaborative research with universities is one of the main aspects for the development and dissemination of knowledge that helps accelerating the internal innovation process in firms [13]. The knowledge transfer between universities and companies allows the companies to survive on the quickly changing competitive market.

\section{CEMEX - Cranfield University Research Project Objectives}

As a result of the previously mentioned trends, there is a need to measure key elements besides the four perspectives proposed in the original BSC. Therefore, a collaborative research project between CEMEX and Cranfield University was defined and carried out to design a novel Balanced Scorecard to enable CEMEX measure the impact of collaborative projects with universities applying an Open Innovation model. Additionally, it was highlighted the need to assess how these collaborative projects, 
could also impact the economic, social and environmental axis of sustainable development. Hence, this CEMEX - Cranfield University collaborative research project had the following objectives:

1) To obtain best practices in regards to open innovation to measure collaborative research outputs based on a detailed literature review

2) To develop industrial case studies based on face to face interviews and a survey to design and validate a generic Collaborative Balanced Scorecard for Open Innovation, integrating new perspectives.

The Unit of Analysis to perform the data gathering and document such case studies, as a base to design the Open Innovation Scorecard was: Industry-University collaborative research projects. Therefore, the target was to define new perspectives and measures to design the Scorecard and analyze the result of such collaborations for innovation.

\section{Research Methodology: Applying the Lead Collaborative Research Framework}

The LEAD (Learn, Energize, Apply and Diffuse) framework developed in CEMEX to manage collaborative projects with external partners was applied as follows [14]:

\section{LEARN}

- Extensive literature review to capture the state-of-the-art about industrial opinions regarding their involvement in collaborative R\&D projects with universities.

- The business application of the research's results, literature review on Key Performance Indicators (KPI), Scorecard and Open Innovation.

\section{ENERGIZE}

- Contact companies in UK to arrange interviews.

- Design, send and apply a structured questionnaire to obtain the lessons learned about their experiences and results when developing collaborative $R \& D$ projects with universities. In other words, how the research results were applied for business outcomes and how they were measured in terms of qualitative and quantities performance. Hence, with the help of the questionnaire, identify potential industrial's KPI's to measure the impact of collaborative R\&D projects with Universities.

- Synthesize the industrial best practices to implement collaborative R\&D out comes and measure the performance.

- Map the current literature of KPI against the industrial KPI from the questionnaire to measure the impact of collaborative research projects with universities.

- Propose a set of KPI (measures) to be integrated in the balanced scorecard for open innovation.

\section{APPLY}

- Design a matrix type of collaborative scorecard for open innovation to measure the impact on research results with universities on companies' performance with the help of literature and questionnaire results.

- Validate the collaborative balanced scorecard in two different companies. 
- Based on Cranfield University results, develop a customised balanced scorecard for CEMEX to be applied in research and networking of Processes and IT.

\section{DIFFUSE}

- Disseminate the results internally in CEMEX and generic outcomes in international conferences and journals

\section{Case Studies and Research Results}

During the energize phase of the LEAD methodology, a questionnaire was designed to capture the industrial needs of collaborative $R \& D$ projects with universities. The firms' information enabled to design the Collaborative Balanced Scorecard for Open Innovation. Ten British companies from different sectors participated in this study. They are:

1. Airbus: One of the world's leading aircraft manufacturers

2. Kodak: Multinational for its imaging innovations in cameras and printers

3. Skill2Learn: SME doing serious business games

4. Bookham: Leading developer and manufacturer of optical solutions

5. Smart Technology Limited: Company that manufactures and develops products based on smart materials

6. I-I-Ice Refrigeration: Refrigeration and air conditioning

7. SKF: Leading global supplier of products and services related to rolling bearings, seals, mechatronics and lubrication systems

8. Aerospace: Global business providing integrated power systems for use on land, at sea and in the air

9. Caltec: Company that designs, develops and supplies equipment for improving production from oil and gas wells.

10. Nissan Technical Centre: Global car manufacturer.

The main findings of the face to face interviews were [15]:

1. Companies have different aims when applying Open Innovation models, but the most important aim is to create new technology, as shown in Figure 2.

2. Most of the companies believe that getting intellectual capital and developing knowledge relationships are the main benefits of collaborating with universities.

3. Another benefit was to generate more business by creating new products by collaborating with universities.

4. Most of the companies have always used peer review to measure research impact and have sometimes used return on investment, financial data analysis and number of patents to measure research impact. In contrast, most of the companies have never used the balanced scorecard or any other tool to measure collaborative research impact. The most common way to measure research impact is the number of publications and by developing satisfaction surveys.

5. The most important balance pairs are: Long/Short term objectives, followed by Financial/Non-Financial measures and by Lag/Lead indicators. 
6. Most companies voted for the creation and dissemination of knowledge, worker efficiency and revenues as the three most important indicators to measure collaborative projects with universities or research institutes.

7. Competitiveness was selected by most of the companies as the most important perspective for collaborative research projects with universities and/or research institutes.

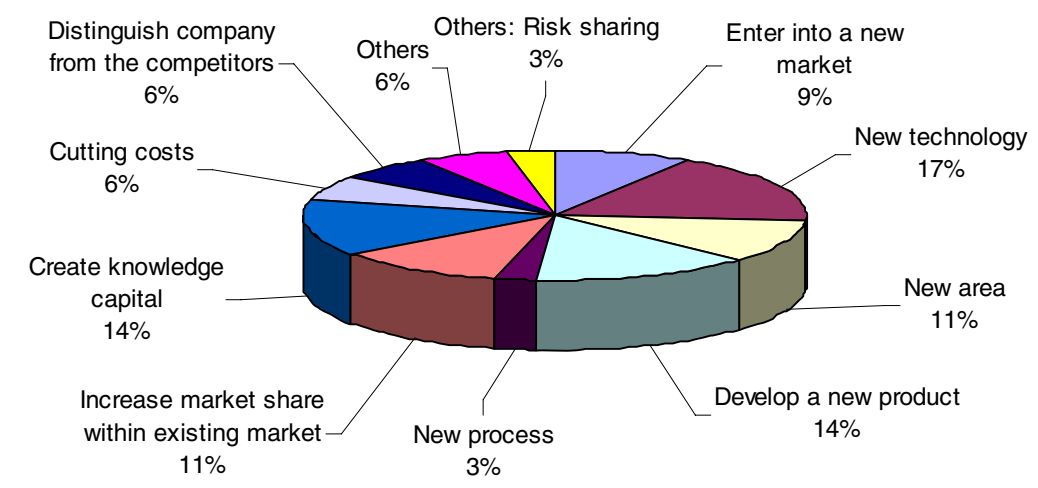

Fig. 2. Key aims of the collaborative research projects with universities based on face to face interviews to ten companies in UK

\section{Proposed Scorecard for Open Innovation for Research and Networking - Processes and IT in CEMEX}

After concluding the collaborative project with Cranfield University, based on the lessons learned of the 10 British Companies interviewed in the project, the following six BSC perspectives have been proposed by the Research and Networking area at Processes and IT Department [16] as follows:

1. Competitiveness: The ability to develop and implement new business models, tools, frameworks and methodologies for CEMEX to optimise its internal working practices and business processes performance.

2. Sustainable Development: Capacity to impact the environmental, social and economical concerns in each of the new collaborative projects with universities, integrating CEMEX key internal and external stakeholders.

3. Innovation: New value creation by developing new services, processes and intangible assets in CEMEX.

4. Strategic Partnerships: The development of new partnerships with external organisations, such as universities, consulting companies or associations in order to develop in a collaborative way new knowledge and innovation outputs.

5. Human Capital: Capacity to develop, share and diffuse new knowledge that can contribute to the company's growth and success. Support the formation of young scientists and researchers to then identify new talent for CEMEX while collaborating with students in universities. 
6. Internal Business Processes: Processes that CEMEX requires in order to share and apply the collaborative research results during and after the conclusion of collaborative projects.

Each one of the proposed Balanced Scorecard's perspectives has objectives to achieve and there are certain relationships among them, for example creating new intellectual capital will increase new technology development in a firm. These cause and effect relationships among the objectives are shown in Figure 3. Some of the most relevant Key Performance Indicators (KPI's) as part of the "measures" element proposed to track and assess the performance of Open Innovation initiatives carried out by the Research and Networking area at Processes and IT in CEMEX [15] are:

\section{1) Competitiveness}

- Annual budget invested in collaborative Research and Development (R\&D)

- Number of new business models or frameworks developed and implemented through collaborative projects per year to support the business and IT evolution in CEMEX

\section{2) Sustainable Development}

- Number of collaborative projects that improved environmentally or socially any region, community, or CEMEX facility

- Number of key internal and external stakeholders integrated in collaborative projects to improve sustainability concerns in the construction value chain

- Number of projects that developed new models, methods and/or standards to improve sustainability practices: health and safety, recycling methods, sustainable construction, etc

- Number of Knowledge Transfer Sessions organized to present Sustainability trends, novel technologies, etc

\section{3) Innovation}

- Number of intangibles per year as a result of collaborative projects with universities, in the form of patents, licenses, copyrights, trademarks, etc

\section{4) Strategic Knowledge Partnerships}

- Number of partnerships with which strategic collaborative projects are developed.

- Number of collaborative projects with universities per year

- Number of collaborative projects with consulting companies per year

- Number of successful proposals developed collaboratively to obtain external funding, such as the European Seventh Research Framework (FP7)

- Number of projects funded by external organisations

- Number of joint publications in scientific journals or conferences

\section{5) Human Capital}

- Number of new highly skilled employees per year hired in CEMEX as a result of collaborative projects, for instance students that participated in collaborative projects (attracting new talent) 
- Number of CEMEX employees attending Knowledge Transfer Sessions (KTS) developed during and after collaborative projects

- Number of international conferences where CEMEX employees have attended to track trends and develop new projects

\section{6) Internal Business Processes}

- Number of new best practices developed and adopted in the company per year in each business process

- Number of improvements done to key End-to-End processes embedded in the CEMEX Business Process Architecture (BPA).

- Number of new tools, methodologies and methods developed to improve any internal business process to increase its efficiency as a result of a collaborative project with external partners

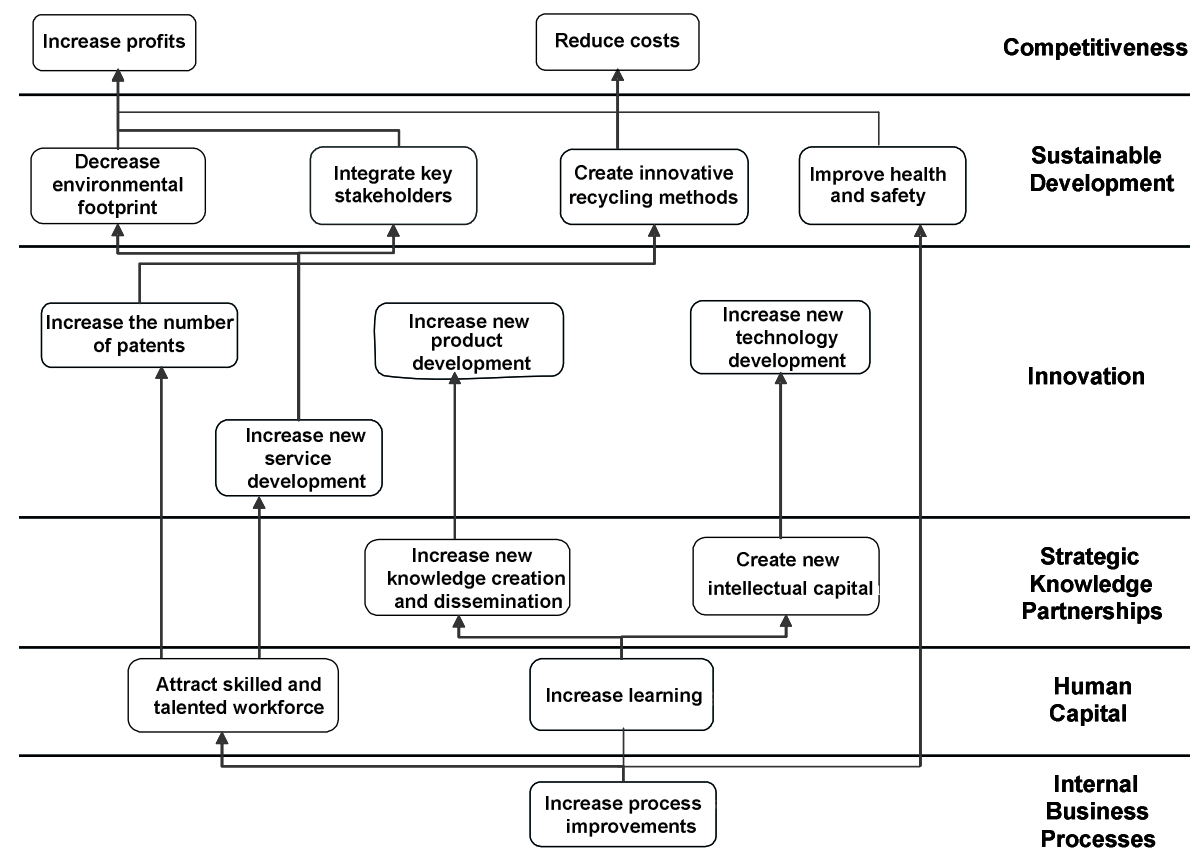

Fig. 3. Cause and effect relationships among the proposed Collaborative Balanced Scorecard objectives identified for CEMEX Research and Networking

\section{Conclusions}

A Balanced Scorecard to measure the impact of collaborative research projects was not available in the literature and is a current need for many companies to enable an open innovation model. Therefore, during this collaborative research project, a structured questionnaire was developed to obtain industrial requirements to design a novel scorecard that integrates the collaborative aspect with universities and other external partners. 
Ten British companies from different sectors participated in this study. As a result, a generic collaborative scorecard for open innovation was designed. Based on this collaborative research outcome, CEMEX customised the findings to its specific strategic needs and defined different Key Performance Indicators (KPIs) in six perspectives to measure its current open innovation initiatives for Research and Networking in Processes and IT. This BSC for Open Innovation in CEMEX is still in the diffusion and implementation phases.

\section{References}

1. Kaplan, R., Norton, D.: Translating Strategy into Action: The Balanced Scorecard. Harvard Business School Press, Boston (1996)

2. Balanced Scorecard Institute: Balanced Scorecard Strategic Planning \& Management Terminology (2008), http: / / www . balancedscorecard. org

3. NetMBA Business Knowledge Center, The Balanced Scorecard (2009), http: / / www . netmba.com/accounting/mgmt/balanced-scorecard

4. Niven, P.: Balanced Scorecard step-by-step: Maximizing Performance and Maintaining Results. John Wiley \& Sons, Inc., Chichester (2002)

5. Voelpel, S.C., Leibold, M., Eckhoff, R.A.: The tyranny of the Balanced Scorecard in the innovation economy. Journal of Intellectual Capital 7(1), 43-60 (2006)

6. Gama, N., Mira da Silva, M., Ataíde, J.: Innovation Scorecard: A Balanced Scorecard for Measuring the Value Added by Innovation. In: Cunha, P.F., Maropoulos, P.G. (eds.) Digital Enterprise Technology Perspectives and Future Challenges. Springer, Heidelberg (2007)

7. Chesbrough, H.: Open innovation: the new imperative for creating and profiting from technology. Harvard Business School Press, Boston (2006a)

8. Viskari, S.: Managing Technologies in Research Organization: Framework for Research Surplus Portfolio, Research Report 176, Masters Thesis, Lappeenranta University of Technology, Lappeenranta (2006), http : / / www . openinnovation. eu

9. Camarinha-Matos, L., Afsarmanesh, H.: Collaborative networks: a new scientific discipline. Journal of Intelligent Manufacturing 16, 439-452 (2005)

10. Romero, D., Galeano, N., Molina, A.: Virtual Organisation Breeding Environments Value System and its Elements. Journal of Intelligent Manufacturing (2007), doi:10.1007/ s10845-008-0179-0

11. Chesbrough, H.: Open Business Models, How to Thrive in the New Innovation Landscape. Harvard Business School Press, Boston (2006)

12. Flores, M.: Developing Collaborative Networks for Research and Innovation in Business Processes and IT Services. Internal CEMEX Research Group (CRG) Newsletter (2008)

13. Flores, M.: Industry - University Collaboration for Innovation and Regional Development: Evidence from Madras, Monterrey, Milan and Lausanne. PhD Thesis, Politecnico di Milano (2006)

14. Flores, M.: The LEAD Research Methodology to manage collaborative open innovation projects. CEMEX internal document (2008)

15. Magyar, A.: Measuring Impact of Research Projects on Company Performance. MSc Thesis, Cranfield University (2008)

16. Flores, M.: Developing a new Balanced Scorecard to measure collaborative research outputs. Internal CEMEX Research Group (CRG) Whitepaper (2009) 